\title{
Influence of moisture conditions on dentin bond strength of single-step self-etch adhesive systems
}

\author{
Yasushi Chiba' ${ }^{1)}$, Akitomo Rikuta ${ }^{2,3)}$, Genta Yasuda ${ }^{1)}$, Akira Yamamoto ${ }^{1)}$, \\ Toshiki Takamizawa ${ }^{2,3)}$, Hiroyasu Kurokawa ${ }^{2,3)}$, Susumu Ando ${ }^{2,3)}$ \\ and Masashi Miyazaki ${ }^{2,3)}$ \\ ${ }^{1)}$ Nihon University Graduate School of Dentistry, Tokyo, Japan \\ ${ }^{2)}$ Department of Operative Dentistry, Nihon University School of Dentistry, Tokyo, Japan \\ ${ }^{3)}$ Division of Biomaterials Science, Dental Research Center, \\ Nihon University School of Dentistry, Tokyo, Japan
}

(Received 14 June and accepted 13 July 2006)

\begin{abstract}
This study was conducted to clarify the influence of dentin surface moisture on bond strength of single-step self-etch adhesive systems. The adhesive systems used were Adper Prompt L-Pop (AP), Clearfil tri-S Bond (CT), Fluoro Bond Shake One (FB), GBond (GB), and One-Up Bond F Plus (OF). Bovine mandibular incisors were wet-ground with \#600 SiC to expose the labial dentin. After rinsing with tap water, the dentin surface was dried with air for 10 sec (Dry condition) or blotted (Wet condition). Adhesives were applied according to each manufacturer's instructions, followed by resin composite polymerization. Ten samples per test group were stored in distilled water at $37^{\circ} \mathrm{C}$ for $24 \mathrm{~h}$, then shear tested at a crosshead speed of $1.0 \mathrm{~mm} / \mathrm{min}$. The data were analyzed by Student's $t$ test and Tukey HSD test at a probability level of 0.05 . The mean bond strengths for Dry condition ranged from 13.9 MPa to 18.2 MPa, and those for Wet condition ranged from 7.1 MPa to 18.4 MPa. Significantly lower bond strengths were obtained for the Wet condition for GB, FB, and OF. Failure after the test was commonly due to adhesive breakdown associated with partial cohesive failure in the dentin. These data suggest that air-drying of the dentin surface is appropriate for the adhesive systems tested. (J. Oral Sci. 48, 131-137, 2006)
\end{abstract}

Correspondence to Dr. Masashi Miyazaki, Department of Operative Dentistry, Nihon University School of Dentistry, 18-13 Kanda-Surugadai, Chiyoda-ku, Tokyo 101-8310, Japan Tel: +81-3-3219-8141

Fax: +81-3-3219-8347

E-mail: miyazaki-m@dent.nihon-u.ac.jp
Keywords: dentin; bond strength; dentin moisture; single-step self-etch system.

\section{Introduction}

Good marginal adaptation to the entire tooth surface is believed to reduce marginal discoloration and pulpal irritation related to microleakage. A bonding system that bonds to the tooth with sufficient strength to withstand internal and external stresses has been sought for a long time. Since the introduction of the acid etch technique for bonding to enamel surfaces (1), many attempts have been made to develop restorative materials for both enamel and dentin (2). The development of a promising bonding system is dependent on understanding the mechanism of bonding and the characteristics of the bonding interface between resin composites and tooth substrates. Compared to the clinical success of enamel bonding, achievement of a predictable and clinically durable dentin bonding system that resists polymerization contraction has been more of a challenge. A number of factors associated with dentin bonding are responsible for this difficulty, including the higher organic content of dentin, fluid pressure from the dentinal tubules, and the presence of a smear layer (3-5). The smear layer prevents infiltration of monomers into dentin, and even if this layer is removed with acid etching followed by application of a bonding agent, fluid flow from the pulp may interfere with stable bonding. To facilitate resin monomer penetration into acid-conditioned dentin, a dentin primer has been introduced for adhesive dentistry (6). 
Since bonding procedures require multiple-step clinical approaches, the clinical success achieved with these adhesive systems sometimes depends on technique-sensitive and material-related factors (7). In an effort to simplify such bonding procedures, several new adhesive systems relying on simultaneous etching of enamel and dentin with phosphoric acid or a self-etching primer have been developed. Systems that use phosphoric acid are called selfpriming adhesive systems or one-bottle adhesive systems $(8,9)$. They combine the functions of the dentin primer and bonding agent of three-step systems. Self-etching primer systems combine the tooth surface etching and priming steps to allow enamel and dentin to be treated simultaneously. The self-etching primer, which dissolves the smear layer and demineralizes the dentin, is an aqueous mixture of acidic functional monomers with other constituents (10). On the other hand, each system still requires a separate conditioning/priming step, and onebottle adhesive systems require blot-drying of the dentin (11) and multiple application of adhesive. To overcome these shortcomings, single-application bonding systems, which combine the functions of the self-etching primer and adhesive, have been developed $(12,13)$. These products are simply applied to the dentin surface for the prescribed period of time, and light-activated.

The application methods for newly developed bonding systems have been simplified, and the manufacturers' instructions have become clearer for achieving optimum clinical performance. Although such adhesive systems have become simpler, careful management is still required (14-16). The purpose of this study was to clarify the influence of moisture conditions at the dentin surface on bond strength of single-step self-etch adhesive systems.

\section{Materials and Methods}

The following single-application self-etch adhesive systems with a combination of resin composites were used: Adper Plompt L-Pop/Filtek Z250 (AP, 3M ESPE, St. Paul, MN, USA), Clearfil tri-S Bond/Clearfil AP-X (CT, Kuraray Medical, Tokyo, Japan), Fluoro Bond Shake One/Beautifil (FB, Shofu Inc., Kyoto, Japan), G-Bond/ Gradia Direct (GB, GC Corp., Tokyo, Japan), and OneUp Bond F Plus/Palfique Estelite (OF, Tokuyama Dental, Tokyo, Japan), as listed in Table 1. Application protocols suggested by each manufacturer are listed in Table 2. All adhesive systems were used in combination with the manufacturers' own restorative resins.

A visible-light activating unit Optilux 501 (sds Kerr, Danbry, CT, USA) was used and the power density (800 $\mathrm{mW} / \mathrm{cm}^{2}$ ) of the curing light was checked with a dental radiometer (Model 100, Demetron) before making the specimens.

Mandibular incisors extracted from 2-3-year-old cattle were used as a substitute for human teeth $(17,18)$. After removing the roots with a low-speed saw (Isomet, Buheler Ltd., Lake Bluff, IL, USA), the pulps were removed, and the pulp chamber of each tooth was filled with cotton to avoid penetration of the embedding media. The labial surfaces of bovine incisors were ground on wet 240-grit $\mathrm{SiC}$ paper to a flat dentin surface. Each tooth was then mounted in cold-curing acrylic resin (Tray Resin II, Shofu Inc., Kyoto, Japan) to expose the flattened area and placed in tap water to reduce the increase of temperature resulting from the exothermic polymerization reaction. The final finish was accomplished by grinding on wet 600 -grit $\mathrm{SiC}$ paper.

After ultrasonic cleaning with distilled water for $1 \mathrm{~min}$ to remove the excess debris, these surfaces were washed and dried with oil-free compressed air for $10 \mathrm{sec}$ (Dry condition) or blotted with filter paper (Wet condition). The adhesive was then applied to the dentin surface according to the manufacturers' instructions. A Teflon (Sanplatec Corp, Osaka, Japan) mold, $2.0 \mathrm{~mm}$ high and $4.0 \mathrm{~mm}$ in diameter was used to form and hold the restorative resin on the dentin surface. The resin composite was condensed into the mold and cured for $40 \mathrm{sec}$. The finished specimens were transferred to distilled water and stored at $37^{\circ} \mathrm{C}$ for $24 \mathrm{~h}$.

Ten specimens per group were tested in a shear mode using a shear knife edge testing apparatus in an Instron testing machine (Type 4204, Instron Corp., Canton, MA, USA) at a cross-head speed of $1.0 \mathrm{~mm} / \mathrm{min}$. Shear bond strength values in MPa were calculated from the peak load at failure divided by the specimen surface area. After testing, the specimens were examined using an optical microscope SZH-131 (Olympus Ltd., Tokyo, Japan) at a magnification of $\times 10$ to define the location of the bond failure (17). The type of failure was determined based on the percentage of substrate-free material: adhesive failure, cohesive failure in the adhesive, or cohesive failure in the dentin.

The results were analyzed by calculating the mean shear bond strength (MPa) and standard deviation for each group. Statistical analysis was done to determine how the bond strengths were influenced by air-drying time. The data for each group were tested for homogeneity of variance using Bartelett's test, and then subjected to ANOVA followed by Tukey's HSD test and Student's $t$ test at a probability level of 0.05 . The statistical analysis was carried out with the Sigma Stat ${ }^{\circledR}$ software system (Ver. 3.1, SPSS Inc., Chicago, IL, USA).

For ultrastructural observation of the resin/dentin 
interface by FE-SEM, bonded specimens stored in distilled water at $37^{\circ} \mathrm{C}$ for $24 \mathrm{~h}$ were embedded in self-curing epoxy resin (Epon 812, Nisshin EM, Tokyo, Japan) and stored at $37^{\circ} \mathrm{C}$ for $12 \mathrm{~h}$. Then the embedded specimens were sectioned to the diameter of the composite resin post and the surfaces of the cut halves were polished with an Ecomet 4/Automet 2 (Buehler Ltd.) using SiC papers of 600, 1200 and 4000-grit size, successively. The surface was finally

Table 1 Materials tested

\begin{tabular}{|c|c|c|c|c|c|}
\hline Code & $\begin{array}{l}\text { Adhesive } \\
\text { (Manufacturer) }\end{array}$ & Main components & Lot No. & Composite & Lot No. \\
\hline $\mathrm{AP}$ & $\begin{array}{l}\text { Adper Prompt L-Pop } \\
\text { (3M ESPE) }\end{array}$ & $\begin{array}{l}\text { Methacrylated phospholic eters, } \\
\text { bis-GMA, CQ, initiator, stabilizer, } \\
\text { HEMA, polyalkenoic acid, water }\end{array}$ & 127613 & $\begin{array}{l}\text { Filtek Surpeme } \\
\text { (A2B) }\end{array}$ & $3 \mathrm{AU}$ \\
\hline $\mathrm{CT}$ & $\begin{array}{l}\text { Clearfil tri-S Bond } \\
\text { (Kuraray Medical) }\end{array}$ & $\begin{array}{l}\text { MDP, bis-GMA, HEMA, initiator } \\
\text { ethanol, stabilizer, filler, water }\end{array}$ & $00021 \mathrm{~A}$ & $\begin{array}{l}\text { Clearfil AP-X } \\
\text { (A2) }\end{array}$ & $00841 \mathrm{~A}$ \\
\hline FB & $\begin{array}{l}\text { Fluoro Bond Shake-One } \\
\text { (Shofu Inc.) }\end{array}$ & $\begin{array}{l}\text { PRG, fluoroaluminosilicate glass, } \\
\text { 4-AET, 4-AETA, bis-GMA } \\
\text { initiator, water }\end{array}$ & $\begin{array}{l}\text { A: } 511 \mathrm{~F}-3 \\
B: 511 \mathrm{~F}-3\end{array}$ & $\begin{array}{l}\text { Beautifil } \\
\text { (A2) }\end{array}$ & 020532 \\
\hline GB & $\begin{array}{l}\text { G-Bond } \\
\text { (GC Corp.) }\end{array}$ & $\begin{array}{l}\text { 4-MET, UDMA, acetone, water } \\
\text { silanated colloidal silica, initiator }\end{array}$ & 0403090 & $\begin{array}{l}\text { Gradia Direct } \\
\text { (A2) }\end{array}$ & 0407051 \\
\hline $\mathrm{OF}$ & $\begin{array}{l}\text { One-Up Bond F Plus } \\
\text { (Tokuyama Dental) }\end{array}$ & $\begin{array}{l}\text { MAC-10, HEMA, MMA, } \\
\text { multifunctionl methacrylic monomer } \\
\text { fliuoroaluminosilicate glass, water } \\
\text { photo initiator, aryl borate catalyst }\end{array}$ & $\begin{array}{l}\text { A: } 003 \\
\text { B: } 004\end{array}$ & $\begin{array}{l}\text { Palfiqu Estelite } \\
\text { (A2) }\end{array}$ & 284 \\
\hline
\end{tabular}

bis-GMA: 2,2bis[4-(2-hydroxy-3-methacryloyloxypropoxy)phenyl] propane, CQ: dl-camphorquinone, HEMA: 2-hydroxyethyl methacrylate, MDP: 10-methacryloxydecyl di-hydrogen phosphate, PRG: pre-reacted glass filler, 4-AET: 4-acryloyloxyethyl trimellitic acid, 4-AETA: 4-acryloyloxyethyl trimellitate anhydride, 4-MET: 4-methacryloyloxyethyl trimellitate, UDMA: urethane dimethacrylate, MAC-10:11-methacryloxy-1,1-undecandicarboxylic acid

Table 2 Application protocols of adhesive systems tested

\begin{tabular}{ll}
\hline Adhesive system & \multicolumn{1}{c}{ Application protocol } \\
\hline $\begin{array}{l}\text { Adper Prompt L-Pop } \\
\text { (Blister-Packed) }\end{array}$ & $\begin{array}{l}\text { Activate blister pack by emptying the liquid out of the red blister } \\
\text { into the yellow blister. The activated solution was applied to dentin } \\
\text { for 15 sec with moderate finger pressure. Gentle stream of air to } \\
\text { dry and apply second coat of adhesive. Gently air dry and light } \\
\text { irradiation for 10 sec. }\end{array}$ \\
$\begin{array}{l}\text { Clearfil tri-S Bond } \\
\text { (Single Bottle) }\end{array}$ & $\begin{array}{l}\text { Dispense one drop of liquid into well. Apply to dentin for } 20 \text { sec. } \\
\text { Relatively strong stream of air to dry and light irradiation for } 10 \text { sec }\end{array}$ \\
$\begin{array}{l}\text { Fluoro Bond Shake One } \\
\text { (Two Bottles) }\end{array}$ & $\begin{array}{l}\text { Mix equal amounts of bond agent A and B. Apply to dentin for } \\
\text { 20 sec. Briefly air dry and light irradiation for 10 sec. }\end{array}$ \\
$\begin{array}{l}\text { G-Bond } \\
\text { (Single Bottle) }\end{array}$ & $\begin{array}{l}\text { Apply sufficient amount of adhesive for 10 sec. Strong air dry } \\
\text { and light irradiation for 10 sec. }\end{array}$ \\
$\begin{array}{l}\text { One-Up Bond F Plus } \\
\text { (Two Bottles) }\end{array}$ & $\begin{array}{l}\text { Mix equal amounts of the bond agents A and B for until a pink } \\
\text { homogenous liquid mixture was obtained. Apply to dentin for }\end{array}$ \\
& 10 sec with agitation and light irradiation for 10 sec. \\
\hline
\end{tabular}


polished on a special soft cloth with diamond paste (Buehler Ltd.) with a grit size of $0.1 \mu \mathrm{m}$. All the SEM specimens were dehydrated in ascending concentrations of tertbutanol (50\% for $20 \mathrm{~min}, 75 \%$ for $20 \mathrm{~min}, 95 \%$ for $20 \mathrm{~min}$, and $100 \%$ for $2 \mathrm{~h}$ ), and then transferred to a critical-point dryer for $30 \mathrm{~min}$. These surfaces were then subjected to argon-ion beam etching (Type EIS-200ER, Elionix Ltd., Tokyo, Japan) for $30 \mathrm{sec}$ with the ion beam (accelerating voltage $1.0 \mathrm{kV}$, ion current density $0.4 \mathrm{~mA} / \mathrm{cm}^{2}$ ) directed perpendicular to the polished surface. The surfaces were coated in a vacuum evaporator, Quick Coater Type SC701 (Sanyu Denshi Inc., Tokyo, Japan), with a thin film of gold. The specimens were finally observed in a FE-SEM (ERA 8800FE, Elionix Ltd.).

\section{Results}

The results of the shear bond strength tests with different dentin moistures are shown in Table 3. The dentin bond strengths for the Dry condition ranged from 13.9 MPa to 18.2 MPa, whereas those for the Wet condition ranged from 7.1 MPa to 18.4 MPa. For both conditions, the highest bond strength was obtained with CT. The bond strengths of each bonding system except for CT were significantly lower $(P<0.05)$ when the dentin surface was blotted. Failure after the test was commonly due to adhesive breakdown associated with partial cohesive failure in the dentin. Adhesive failure was the predominant mode of failure for the specimens in the Wet condition.
The results of FE-SEM observations of the resin/dentin interface under Dry and Wet conditions are shown in Figs. 1 (CT) and 2 (OF). These observations seemed to correspond to the results of the dentin bond strength tests. For the systems showing lower bond strengths in the Wet condition, gaps between the adhesive and dentin were observed (Fig. 2). On the other hand, no gap between the adhesive and dentin was observed for the adhesive system CT (Fig. 1).

\section{Discussion}

The clinical performance of dentin bonding systems has been improved, allowing a high clinical retention rate. In clinics, many factors affect the marginal integrity of restorations, resulting in marginal leakage (7). In addition, nano-leakage caused by insufficient resin penetration into prepared dentin has been documented $(19,20)$. The micromechanical entrapment of resin in the dentin through interdiffusion is one of the keys to optimization of bond strength. As the forces exerted clinically on restorations or teeth are complex in nature, neither tensile nor shear bond strength tests simulate the intraoral forces sufficiently well. However, bond strength tests may still provide useful information on procedural changes, even though the bond strength values themselves may have little meaning (21). With these considerations in mind, it seems useful to study the technique-sensitive factors related to dentin bond strength.

Table 3 Influence of dentin surface moisture on shear bond strength (in MPa) of single-step self-etch systems

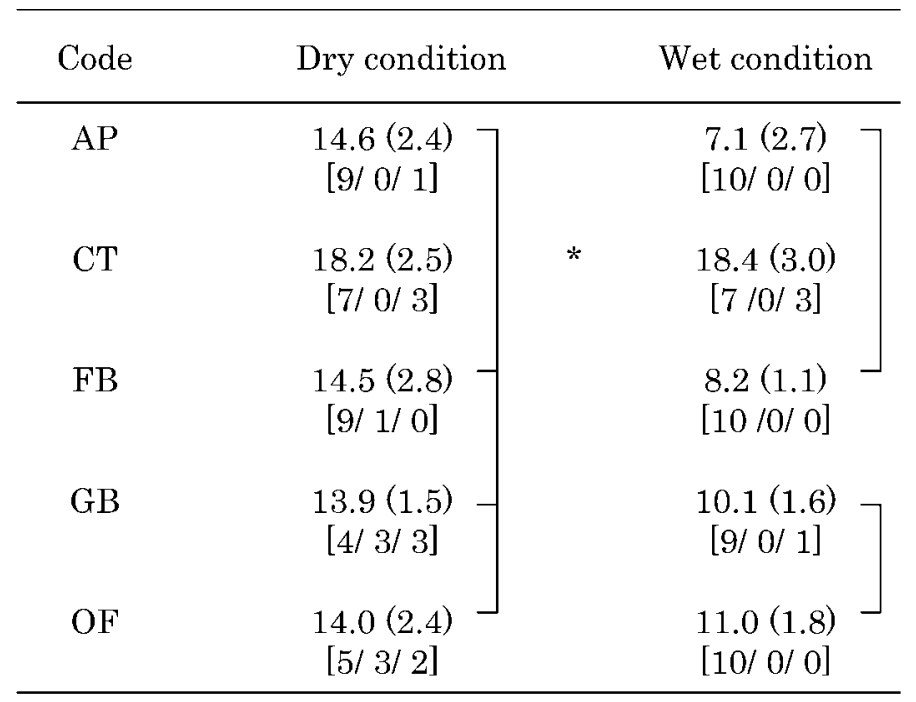

$\mathrm{N}=10$, Values in parenthesis are standard deviation.

*: No significant difference was found between Dry and Wet conditions $(P>0.05)$

Values connected by vertical lines indicate no significant difference $(P>0.05)$.

Failure mode: [adhesive failure/cohesive failure in resin/cohesive failure in dentin] 
It has been demonstrated that the presence of water in the dentin surface enhances the bond strength obtained with the wet bonding technique (11). The bonding agent of the one-bottle adhesive system is a hydrophilic solution that is extremely effective in wetting the etched dentin. The adhesive penetrates the exposed collagen network and the dentinal tubules, and sets hard upon evaporation of the solvents. The solvent of the bonding agent dynamically replaces the water until an equilibrium is established. If the etched dentin dries excessively after the etching agent has been rinsed off, penetration of the adhesive resin may be obstructed by the collapsed collagen fibers. Thus the diffusion of the adhesive resin through the entire thickness of the etched dentin might be incomplete, resulting in a

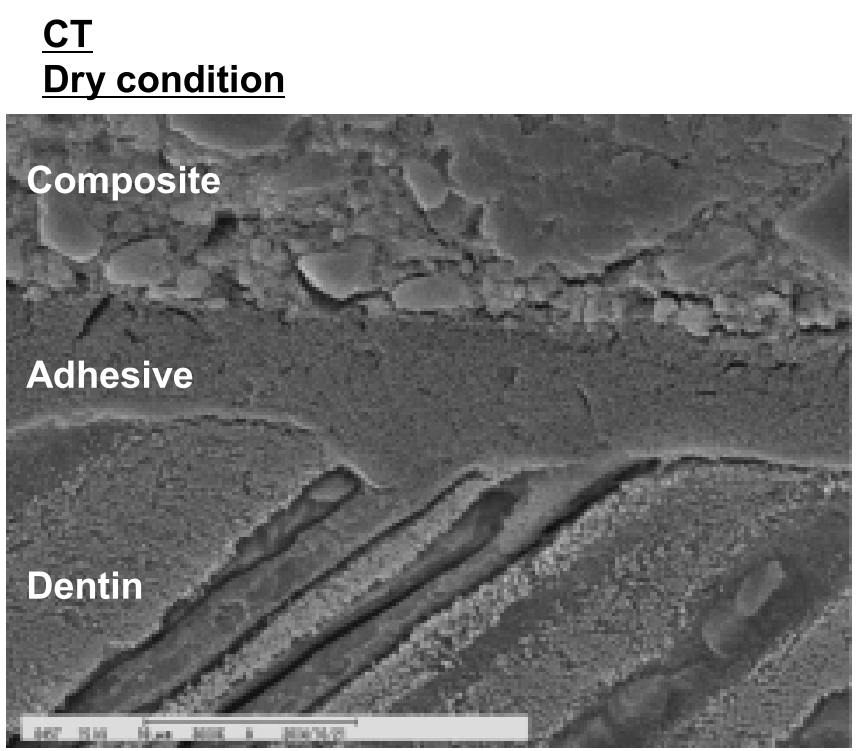

Fig. 1 SEM photomicrographs of resin/dentin interface of CT.

\section{OF \\ Dry condition}

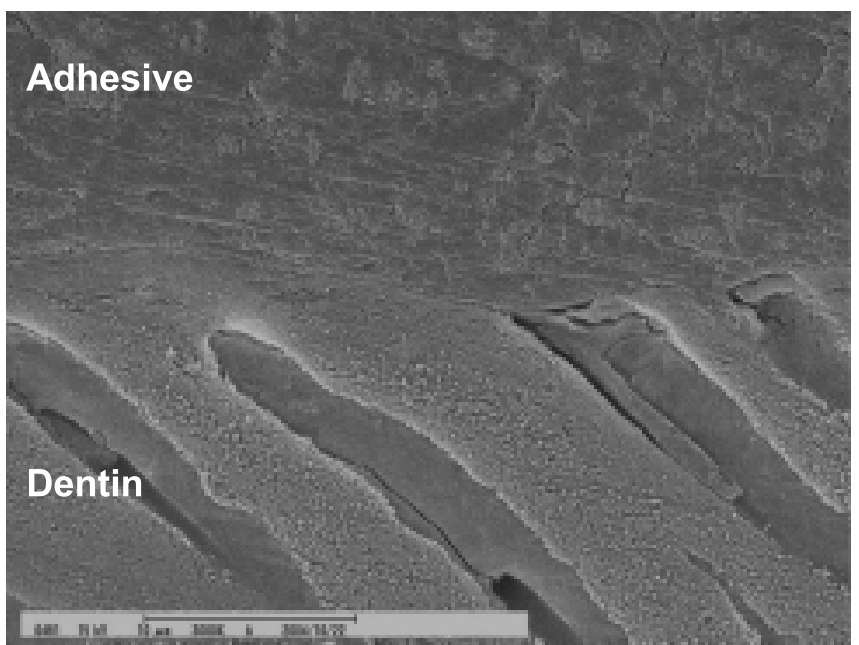

Fig. 2 SEM photomicrographs of resin/dentin interface of OF. decrease of bond strength. On the other hand, if the dentin surface remains too wet, the so-called "over-wet phenomenon" might occur, and formation of a hybrid layer might be prevented by phase separation of the hydrophobic components of the bonding agent (22-24). The moisture on the dentin surface plays an important role in preventing the collapse of collagen fibers after acid conditioning. It is difficult to decide the appropriate extent of wetness in a clinical situation, when a more complex cavity formation is present.

The influence of intrinsic dentinal fluid on bonding efficacy has been investigated with simulated pulpal fluid $(25,26)$. Investigation of dentin surface moisture during the bonding procedure is another relevant clinical aspect.

\section{CT}

\section{Wet condition}

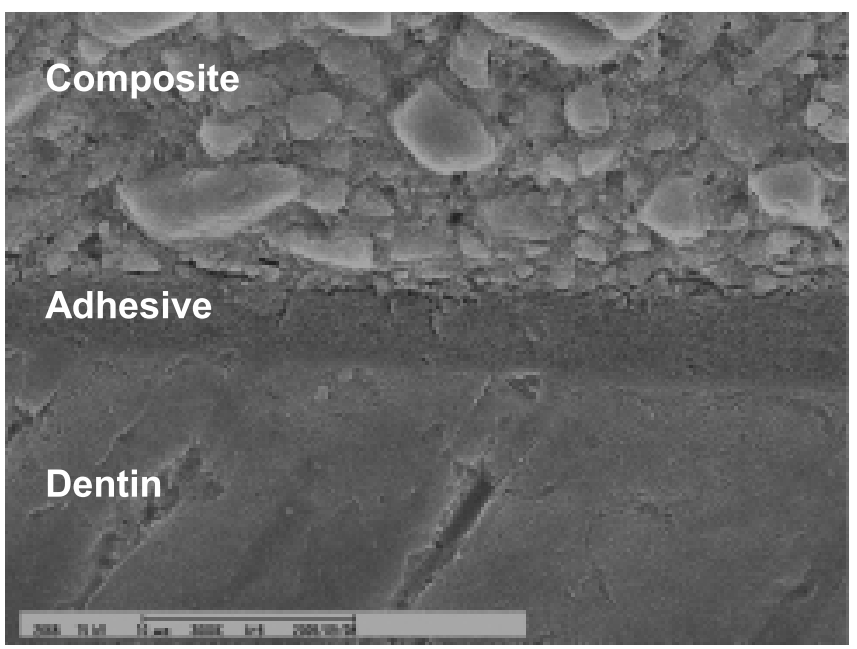

\section{OF}

Wet condition

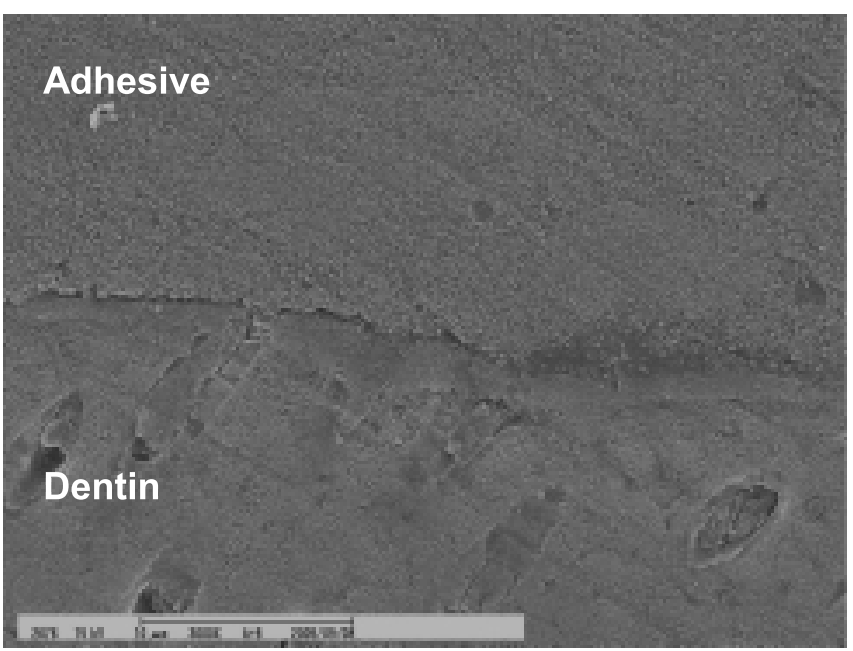


Resin composites might be susceptible to moisture at the dentin surface, which has shown to decrease bond strength. The results of this study suggested that the influence of extrinsic dentin wetness differed among the bonding systems tested, and four out of five adhesive systems were more sensitive to moisture at the dentin surface. An explanation for the reduction in bond strengths is that the moisture on the dentin surface might dilute the adhesives applied to the dentin, thus negating the etching effect of the adhesive. Such imperfect etching of the dentin surface by the adhesive and decrease in the potential for hybridization with the dentin may lead to failure of the resin composite.

Another explanation for the decrease in dentin bond strength might be imperfect polymerization of adhesives due to excessive water present on the dentin surface. Adequate bonding of a resin composite to dentin depends not only on penetration of the adhesive into the dentin to create a resin-dentin interdiffusion zone, but also on the mechanical properties of the adhesive. It has been reported that the use of filled bonding agents could improve bond strength, because the incorporation of a micro-filler into the bonding agent strengthens its mechanical properties (27). Hypothetically, stronger resins might lead to stronger bonding to dentin (28). The strength of cured adhesive resin is dependent on the composition, degree of conversion, and length of the polymer chain. Unreacted resin monomer remaining in adhesive resins may alter their mechanical properties (29). Thus, evaporation of water present on the dentin surface is important for achieving optimum bond strength.

While significant decreases in bond strength were observed for other adhesive systems, TS showed no change in bond strength regardless dentin surface moisture conditions. This may have been related to the chemical nature of this adhesive system. A previous study that compared the chemical bonding efficacy of functional monomers demonstrated that a phosphate monomer had a high capacity for chemical bonding to hydroxyapatite over a clinically feasible application period. Furthermore, the calcium salt created by the phosphate monomer was highly insoluble. According to the adhesion-decalcification concept $(30,31)$, the less soluble the calcium salt of an acidic molecule, the more intense and stable the molecular adhesion to a hydroxyapatite-based substrate. Thus the superior bonding performance of functional monomers might be reflected in their actual capacity for adhesive bonding to dentin. Accordingly, no change in bond strength was observed for the CT.

However, the present findings should be interpreted with caution, as the results were obtained under laboratory conditions and it remains to be seen whether a similar trend occurs in vivo. It is crucial for general practitioners who use these adhesive systems to understand the factors that contribute to the durability of the restorations and to be aware of their bonding characteristics.

\section{Acknowledgments}

This work was supported, in part, by a Grant-in-Aid for Scientific Research (C) 17592004 from the Japan Society for the Promotion of Science, and by Grants-in-Aid for Young Scientists (B) 16791164 and 17791370 from the Ministry of Education, Culture, Sports, Science and Technology of Japan, by the Sato Fund from Nihon University School of Dentistry, and by a grant from the Dental Research Center, Nihon University School of Dentistry.

\section{References}

1. Buonocore MG (1995) A simple method of increasing the adhesion of acrylic filling materials to enamel surfaces. J Dent Res 34, 849-853

2. Van Meerbeek B, De Munck J, Yoshida Y, Inoue S, Vargas M, Vijay P, Van Landuyt K, Lambrechts P, Vanherle G (2003) Buonocore memorial lecture. Adhesion to enamel and dentin: current status and future challenges. Oper Dent 28, 215-235

3. Nikaido T, Burrow MF, Tagami J, Takatsu T (1995) Effect of pulpal pressure on adhesion of resin composite to dentin: bovine serum versus saline. Quintessence Int 26, 221-226

4. Marshall GW Jr, Marshall SJ, Kinney JH, Balooch M (1997) The dentin substrate: structure and properties related to bonding. J Dent 25, 441-458

5. Pashley DH, Carvalho RM (1997) Dentine permeability and dentine adhesion. J Dent 25, 355372

6. Chigira H, Yukitani W, Hasegawa T, Manabe A, Itoh K, Hayakawa T, Debari K, Wakumoto S, Hisamitsu H (1994) Self-etching dentin primers containing phenyl-P. J Dent Res 73, 1088-1095

7. Van Meerbeek B, Van Landuyt K, De Munck J, Hashimoto M, Peumans M, Lambrechts P, Yoshida Y, Inoue S, Suzuki K (2005) Technique-sensitivity of contemporary adhesives. Dent Mater J 24, 1-13

8. Ferrari M, Gorracci G, Garcia-Godoy F (1997) Bonding mechanism of three "one-bottle" system to conditioned and unconditioned enamel and dentin. Am J Dent 10, 224-230

9. Swift EJ Jr, Wilder AD Jr, May KN Jr, Waddell SL (1997) Shear bond strengths of one-bottle dentin adhesives using multiple applications. Oper Dent 22, 
194-199

10. Haller B (2000) Recent developments in dentin bonding. Am J Dent 13, 44-50

11. Kanca J 3rd (1992) Resin bonding to wet substrate. I. Bonding to dentin. Quintessence Int 23, 39-41

12. Swift EJ Jr (2002) Dentin/enamel adhesives: review of the literature. Pediatr Dent 24, 456-461

13. Lopes GC, Baratieri LN, de Andrada MA, Vieira LC (2002) Dental adhesion: present state of the art and future perspectives. Quintessence Int 33, 213224

14. Asaka Y, Miyazaki M, Takamizawa T, Tsubota K, Moore BK (2006) Influence of delayed placement of composites over cured adhesives on dentin bond strength of single-application self-etch systems. Oper Dent 31, 18-24

15. Chiba Y, Yamaguchi K, Miyazaki M, Tsubota K, Takamizawa T, Moore BK (2006) Effect of airdrying time of single-application self-etch adhesives on dentin bond strength. Oper Dent 31, 233-239

16. Yamamoto A, Tsubota K, Takamizawa T, Kurokawa H, Rikuta A, Ando S, Takigawa T,Kuroda T, Miyazaki M (2006) Influence of light intensity on dentin bond strength of self-etch systems. J Oral Sci 48, 21-26

17. Fowler CS, Swartz ML, Moore BK, Rhodes BF (1992) Influence of selected variables on adhesion testing. Dent Mater 8, 265-269

18. Schilke R, Bauß O, Lisson JA, Schuckar M, Geurtsen W (1999) Bovine dentin as a substitute for human dentin in shear bond strength measurements. Am J Dent 12, 92-96

19. Sano H (2006) Microtensile testing, nanoleakage, and biodegradation of resin-dentin bonds. J Dent Res $85,11-14$

20. Hashimoto M, Tay FR, Svizero NR, de Gee AJ, Feilzer AJ, Sano H, Kaga M, Pashley DH (2006) The effects of common errors on sealing ability of total-etch adhesives. Dent Mater 22, 560-568

21. Miyazaki M, Oshida Y, Xirouchaki L (1996) Dentin bonding system. Part I: Literature review. Biomed Mater Eng 6, 15-31
22. Tay FR, Gwinnett AJ, Wei SH (1996) The overwet phenomenon: a optical, micromorphological study of surface moisture in the acid-conditioned, resindentin interface. Am J Dent 9, 43-48

23. Tay FR, Gwinnett AJ, Wei SH (1996) Micromorphological spectrum from overdrying to overwetting acid-conditioned dentin in water-free acetone-based, single bottle primer/ adhesives. Dent Mater 12, 236-244

24. Tay FR, Gwinnett AJ, Wei SH (1997) The overwet phenomenon in two-component acetone-based primers containing aryl amine and carboxylic acid monomers. Dent Mater 13, 118-127

25. Nikaido T, Burrow MF, Tagami J, Takatsu T (1995) Effect of pulpal pressure on adhesion of resin composite to dentin: bovine serum versus saline. Quintessence Int 26, 221-226

26. Belli S, Unlu N, Ozer F (2001) Bonding strength to two different surfaces of dentin under simulated pulpal pressure. J Adhes Dent 3, 145-152

27. Miyazaki M, Ando S, Hinoura K, Onose H, Moore BK (1995) Infuluence of filler addition to bonding agents on shear bond strength to bovine dentin. Dent Mater 11, 234-238

28. Pashley DH, Ciucchi B, Sano H, Carvalho RM, Russell CM (1995) Bond strength versus dentine structure: a modelling approach. Arch Oral Biol 40, 1109-1118

29. Yamada M, Miyazaki M, Moore BK (2004) Influence of interchanging adhesive resins and selfetching primers on the mechanical properties of adhesive resins. Oper Dent 29, 532-537

30. Yoshida Y, Nagakane K, Fukuda R, Nakayama Y, Okazaki M, Shintani H, Inoue S, Tagawa Y, Suzuki K, De Munck J, Van Meerbeek B (2004) Comparative study on adhesive performance of functional monomers. J Dent Res 83, 454-458

31. Yoshioka M, Yoshida Y, Inoue S, Lambrechts $P$, Vanherle G, Nomura Y, Okazaki M, Shintani H, Van Meerbeek B (2002) Adhesion/decalcification mechanisms of acid interactions with human hard tissues. J Biomed Mater Res 59, 56-62 